\title{
Neonatal References: Epidemiology and Prognosis in a Malian Context
}

\author{
Fatoumata L. F. Diakité1 ${ }^{*}$ (1) Djénèba Konaté1, Nouhoum L. Traoré2, Noel Banou1, Lala N. Sidibé1, \\ Oumar Coulibaly1', Belco Maiga', Karamoko Sacko' ${ }^{1}$, Fousseyni Traoré1, Abdoul K. Doumbia', \\ Hawa G. Diall1', Leila Maiga1, Ibrahim Ahamadou1, Alou Traoré3, Adama Koné4, \\ Guediouma Dembélé5, Djita Ba-Sidibé6, Pierre Togo' ${ }^{1}$, Adama Dembélé1, El Mouloud Cissé1, \\ Abdoul A. Diakité1, Boubacar Togo', Mariam Sylla1, Fatoumata Dicko-Traoré1
}

\author{
${ }^{1}$ Department of Pediatrics of the University Hospital Gabriel Toure, Bamako, Mali \\ ${ }^{2}$ Reference Health Center of Commune IV, Bamako, Mali \\ ${ }^{3}$ Pediatrician Doctor Practicing in Private, Bamako, Mali \\ ${ }^{4}$ Hospital Mother-Child "Luxembourg”, Bamako, Mali \\ ${ }^{5}$ Mali Hospital, Bamako, Mali \\ ${ }^{6}$ Reference Health Center of Commune III, Bamako, Mali \\ Email: *leoniediakite@gmail.com
}

How to cite this paper: Diakité, F.L.F., Konaté, D., Traoré, N.L., Banou, N., Sidibé, L.N., Coulibaly, O., Maiga, B., Sacko, K., Traoré, F., Doumbia, A.K., Diall, H.G., Maiga, L., Ahamadou, I., Traoré, A., Koné, A., Dembélé, G., Ba-Sidibé, D., Togo, P., Dembélé, A., Cissé, El M., Diakité, A.A., Togo, B., Sylla, M. and Dicko-Traoré, F. (2021) Neonatal References: Epidemiology and Prognosis in a Malian Context. Open Journal of Pediatrics, 11, 479-489. https://doi.org/10.4236/ojped.2021.113045

Received: July 24, 2021

Accepted: September 12, 2021

Published: September 15, 2021

Copyright $\odot 2021$ by author(s) and Scientific Research Publishing Inc. This work is licensed under the Creative Commons Attribution International License (CC BY 4.0).

http://creativecommons.org/licenses/by/4.0/ (c) (i) Open Access

\begin{abstract}
Neonatal mortality remains a public health problem in Mali. The neonatal referral is a systemic factor determining the neonatal prognosis. This work was initiated to determine the frequency of neonatal referrals and to determine their prognosis. Patients and Methods: A cross-sectional study was carried out from November 1, 2019 to January 31, 2020 in the neonatology service of the pediatrics department of the Gabriel Toure University Hospital in Bamako. All newborns referred by another health structure in the country were included in this stud. All newborns referred by another health structure in the country were included in this study. To determine the risk factors related to the neonatal referral, we performed univariate and multivariate analyzes to determine the odds ratios and fitted with a significant $\mathrm{p}$ probability if $p<0.05$ and the $95 \%$ confidence interval. Results: The frequency of referrals was $54.3 \%$. Newborns came from basic structures in $19.3 \%$ of cases, from tertiary structures in $6.7 \%$. The main reason for transfer was prematurity (40.2\%) followed by perinatal anoxia (15.3\%), malformations (15.3\%), respiratory distress $(15.2 \%)$ and infection neonatal $(9.1 \%)$. The ambulance was the primary means of transfer in $71.3 \%$. In $80 \%$ of cases the transfer had been made within the first 24 hours of life. On admission, a third of the newborns (31.1\%) were less than $1500 \mathrm{~g}$, hypothermic in $43.8 \%$ and febrile in $15.1 \%$. The evolution was marked by $40.2 \%$ of deaths. The analysis of prognostic factors, allowed us to observe that the more the newborn is premature or of low weight the more risk of death was very high with respectively 18.5 times
\end{abstract}


in the less than 28 weeks of amenorrhea (WA) $(\mathrm{ORa}=18.5 ; \mathrm{CI}=1.9-180 ; \mathrm{p}=$ $0.012)$ and 6.6 times in those less than $1000 \mathrm{~g}(\mathrm{ORa}=6.6 ; \mathrm{CI}=1.4-29.7 ; \mathrm{p}=$ $0.015)$. Likewise, any change in body temperature increased risk of death by 1.9 times compared to normothermia. Conclusion: The establishment of a neonatal referral system is necessary to reduce neonatal mortality in our context.

\section{Keywords}

Neonatal References, Epidemiology, Prognosis, Malian Context

\section{Introduction}

Neonatal reference is the transfer of a newborn at a higher level for review and or care. It requires a rigorous organization by a prior call from the reception structure, a means of medical transport and competent medical and paramedical staff to ensure a referral in the best conditions [1] [2] [3]. In France, the organization of perinatal care, on the basis of a regional network, allows in utero transfer of the mother-fetus couple at an optimal level to ensure their complete care. This network organization has enabled a very significant reduction in the number of postnatal referrals [4] [5] [6]. In Mali, the reference system/evacuation of obstetric emergencies has been established since 1993 resulting in a positive impact in reducing maternal mortality [7] [8]. However, it was not until 2002 that the newborn was introduced into this system. Despite everything, neonatal mortality still remains high in our country [7] [8]. Because the system has remained in an embryonic state due to the fact that neonatal references are made without any prior organization and the means of transport are inadequate [7] [8] [9]. In setting up the referral/neonatal evacuation system, the optimal level of care expected must be defined by level of the health pyramid. The Gabriel Toure University Hospital Center is located at the top (tertiary level) of the health pyramid of Mali, which houses within it the country's reference neonatal service ensuring the activities of a neonatal service, neonatal intensive care and neonatal resuscitation [10]. Neonatal mortality remains very high from $28.5 \%$ to $36.8 \%$ [9] [10]. And referrals represent around $60 \%$ to $85 \%$ of our hospitalizations [9] [10] [11] [12]. We receive newborns from all health structures in Bamako and the different regions of the country. It is evident that improving the conditions of transport and transfer of the vitally distressed newborn is an essential factor in reducing neonatal mortality [13] [14]. Thus the reference constitutes a determining factor of the neonatal prognosis. It is with this vision that this work was initiated in order to determine the frequency of neonatal references and clarify their prognosis.

\section{Patients and Methods}

This study took place in the referral neonatal service in Mali, which was created 
in 1999. Until December 2007, it was a resuscitation service providing care for children in vital distress as well as newborns. With annual number of hospitalizations of 4000 infants, or $43 \%$ of hospitalizations of pediatric department and $23 \%$ of all Gabriel Toure University Hospital [11]. We carried out a cross-sectional study over a 3-month period from November 1, 2019 to January 31, 2020 in the neonatology service of the pediatrics department of the Gabriel Toure university hospital center. All newborns referred by another health structure in the country were included. We have excluded all referrals or transfers from the maternity the Gabriel Toure University Hospital, all births at home and newborns brought by their parents. We calculated a minimum sample size $(n)$ by Schwartz's formula: $n=Z(\alpha)^{2} p q / i^{2}$ and we took the prevalence $\mathrm{p}$ at $71 \%$ from the study carried out in the service in 2010 [9] and we found a minimum number of 360 newborns. The variables studied were: gender, residence, source structure, reference purposes, the means of transport used, the consultation period, gestational age (GA), weight, temperature and become immediate. Data collected retrospectively from newborn medical records and service registers. Analysis was done by Statistical Package for Social Sciences (SPSS) version 22. Descriptive analysis was done to determine the frequency of categorical variables. Univariate analysis and logistic regression were performed to determine the neonatal mortality determinants related to the reference. The binary logistic regression at various levels has been adjusted to identify significant neonatal mortality determinants associated with the reference of the newborn, adjusted odds ratio (OR a) with confidence interval (CI) of $95 \%$ and $\mathrm{p}<0.05$ demonstrated that the determinants were statistically significant.

\section{Results}

\subsection{Patient Characteristics and Sociodemographic Conditions of Transfer}

During the study period, referrals represented $54.3 \%$ of hospitalized patients, or 450 out of the 828 newborns in hospital. The sex ratio was 1.4 in favor of the male sex. The most represented places of residence were commune I of the district of Bamako (21.7\%), commune IV (10\%) and the circle of Kalaban Coro (15.1\%). Regarding the structures from which our patients came, from Bamako the patients mainly came from secondary health centers: the Reference Health Centers (RHC) of the district in 50.9\% of cases (especially the CI RHC: $21.6 \%$ and the RHC CV: 9.6\%). Basic health centers: private structures (Clinics/Medical Cabinets) in $12.4 \%$ and Community Health Centers (CHC) represented $6.9 \%$ of referrals. Tertiary structures (hospitals) sent us $6.7 \%$ of our patients. The top five referral reasons were prematurity and its complications (40.2\%), perinatal anoxia (15.3\%), malformations (15.3\%), respiratory distress (15.2\%) and neonatal infections $(9.1 \%)$. In addition to these reasons, the lack of space or oxygen constituted $9.6 \%$ of reasons for transfer to the RHC level. Malformations made up the bulk of referrals from other health facilities in the country (32\%). The means of 
transport used were ambulance (71.3\%), taxi (26.2\%) and personal vehicle (2.5\%). The ambulance was the means of transport most used by the secondary health structures of RHC (89\%) and tertiary (93\%) of the country. The taxi was used by private structures (82\%) and $\mathrm{CHC}(93 \%)$ (Figure 1).

\subsection{Clinical Characteristics of the Patient}

The average transfer time was 18 hours with $80 \%$ of referrals made in the first 24 hours, $67.6 \%$ of which were before the sixth hour of life. Regarding gestational age (GA) birth, the majority were born prematurely $(50.7 \%$ ) of which $6.4 \%$ before the 28th WA. For the admission weight, one third (31.1\%) were less than $1500 \mathrm{~g}$ with $8.4 \%$ less than $1000 \mathrm{~g}$. On arrival, $43.8 \%$ of the newborns were hypothermic $\left(<36^{\circ} \mathrm{C}\right)$ and $15.1 \%$ were febrile. For the prognosis, the immediate course was marked by $40.2 \%$ of deaths. Analysis of mortality according to the structure of origin, we found that $46.8 \%$ of references from the interior of the country died, followed by private structures (44.6\%), RHC of the district (40.2\%), CHC (38.7\%), Kati structures (33.3\%) and hospitals (30\%). For referral reasons, nearly half (48.7\%) referred for neonatal infection died followed by prematurity (44.2\%), respiratory distress (42.6\%), malformations $(36.2 \%)$ and perinatal anoxia $(27.5 \%)$ (Figure 2 ).

\subsection{Prognostic Factors Influencing Mortality}

By doing univariate analysis and logistic regression of certain prognostic factors,

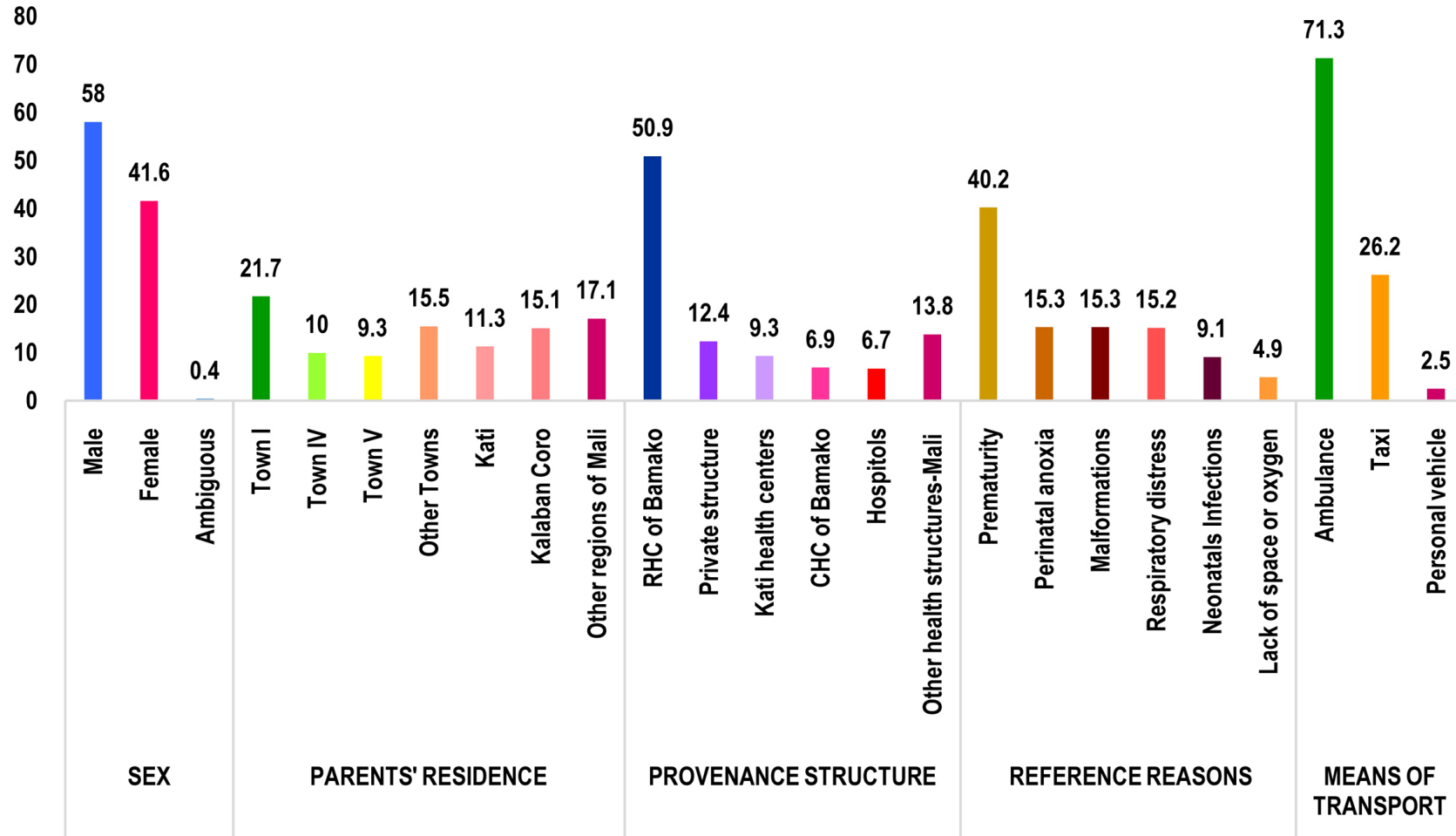

Figure 1. Distribution of patients according to: gender, residence, structure of origin, reason for referral and means of transport used. 


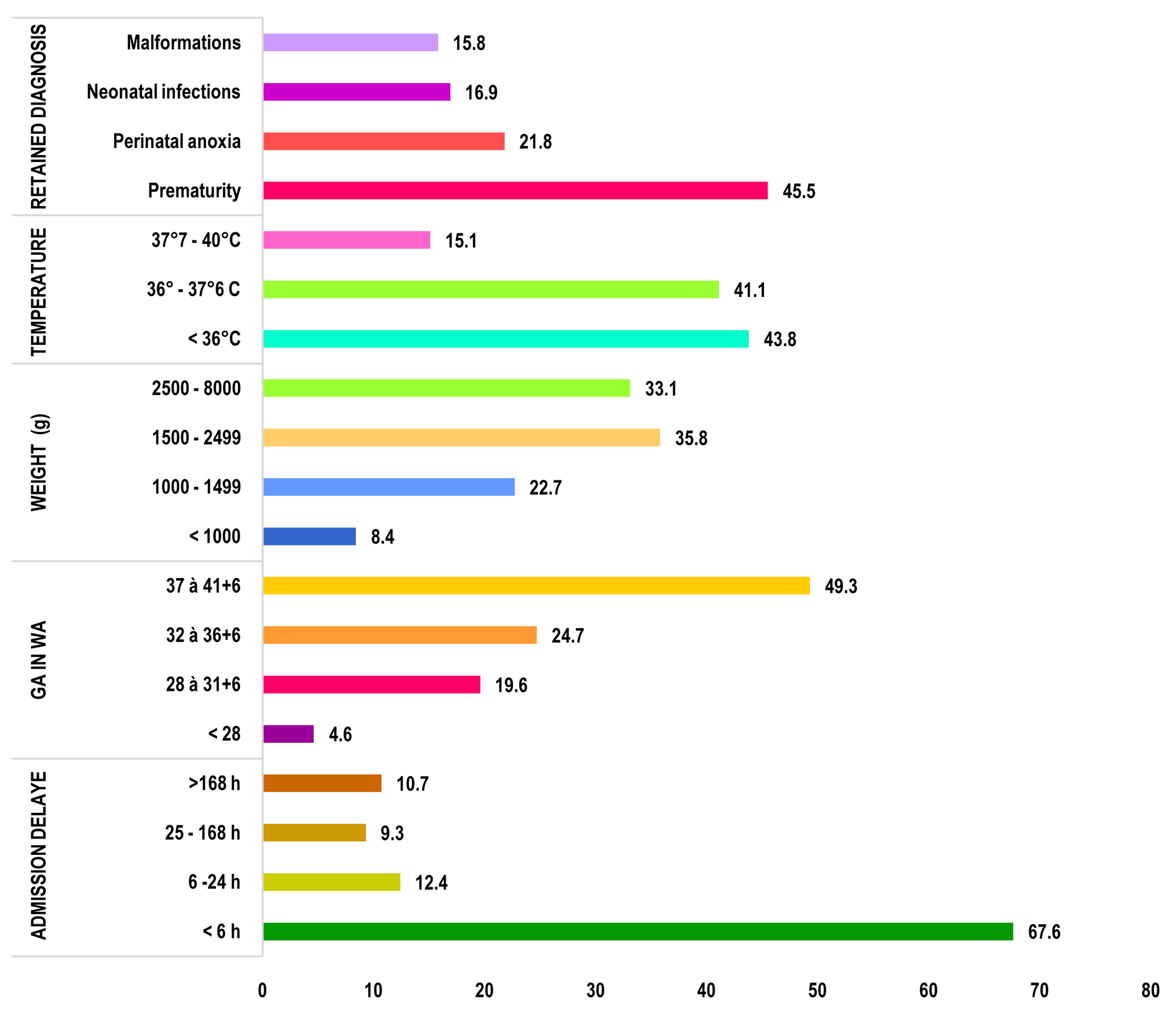

Figure 2. Distribution of functions in patients admission delay, gestational age (GA) of birth weight, the temperature and retained diagnosis.

we observed that the more the newborn was born prematurely the more the risk of death increased, so it was 18.5 times for children under 28th WA (ORa $=18.5$; $\mathrm{CI}=1.9-180 ; \mathrm{p}=0.012)$ versus 2.3 times between 28 and $31 \mathrm{WA}+6(\mathrm{OR}=2.3$ $\mathrm{CI}=1.4-3.8 ; \mathrm{p}=0.001)$ compared to this born at term. The same observation for the weight less than $1000 \mathrm{~g}$ had 6.6 times risk of death $(\mathrm{ORa}=6.6 ; \mathrm{CI}=1.4$ 29.7; $\mathrm{p}=0.015)$ against 2.2 times between $1000 \mathrm{~g}$ and $1499 \mathrm{~g}(\mathrm{OR}=2.2 ; \mathrm{CI}=1.3$ $3.7 ; \mathrm{p}=0.003)$ relative to normal weight. Compared with normothermia, the risk was 1.9 times for hypothermia $(\mathrm{OR}=1.96 ; \mathrm{CI}=1.3-2.9 ; \mathrm{p}=0.002)$ than for fever $(\mathrm{ORa}=1.9 ; \mathrm{CI}=1-3.5 ; \mathrm{p}=0.042)$. Other factors did not influence mortality in our study. For the health structure of origin, we found that there was no statistically significant difference between the base structures (CHC), the reference health centers (RHC), tertiary structures (Hospitals) compared to private structures because the transfer conditions are practically identical. And there 
was no statistically significant difference between transport by ambulance and other means used (Table 1).

\section{Discussion}

\subsection{Characteristics of the Country's Reference System, Transfer Conditions, Patient Clinics}

In developed countries, there are two types of transfer. Transfer in utero to a maternity unit with a neonatal intensive care unit gives better results (mortality, morbidity and long-term sequelae) than a postnatal transfer, especially in a premature newborn [15]. While for the full-term or near-term newborn, postnatal transfer is not always avoidable in cases of unforeseeable per- or postnatal pathology [3] [16]. Our neonatology service at Gabriel Toure University Hospital is the national reference in neonatal care, in recent years we have seen an increase in the number of referrals from $71 \%$ to $84 \%$ (2007 and 2008-2012) then

Table 1. Distribution according to prognostic factors.

\begin{tabular}{|c|c|c|c|c|c|c|c|c|}
\hline \multirow{2}{*}{ Factors } & \multirow{2}{*}{$\begin{array}{l}\% \text { among } \\
\text { deceased }\end{array}$} & \multirow{2}{*}{$\begin{array}{c}\% \text { among } \\
\text { living }\end{array}$} & \multicolumn{3}{|c|}{ Univariate analysis } & \multicolumn{3}{|c|}{ Logistic regression } \\
\hline & & & OR & ICoR & $\mathrm{p}$ & ORa & ICaor & $\mathrm{p}$ \\
\hline \multicolumn{9}{|c|}{ GA in WA } \\
\hline $37-41+6$ & 32.9 & 67.1 & & & & & & \\
\hline$<28$ & 96.6 & 3.4 & 57.2 & $7.6-428$ & $<0.001$ & 18.5 & $1.9-180$ & 0.012 \\
\hline $28-31+6$ & 53.4 & 46.6 & 2.3 & $1.4-3.8$ & 0.001 & 1.4 & $0.5-3.7$ & 0.495 \\
\hline $32-36+6$ & 29.7 & 70.3 & 0.8 & $0.5-1.4$ & 0.561 & 0.7 & $0.3-1.3$ & 0.253 \\
\hline \multicolumn{9}{|c|}{ Admission weight ( $\mathrm{g}$ ) } \\
\hline $2500-8000$ & 28.8 & 71.2 & & & & & & \\
\hline$<1000$ & 89.5 & 10.5 & 20.9 & $7-62.6$ & $<0.001$ & 6.6 & $1.4-30$ & 0.015 \\
\hline $1000-1499$ & 47 & 53 & 2.2 & $1.3-3.7$ & 0.003 & 1.9 & $0.7-4.9$ & 0.179 \\
\hline $1500-2499$ & 34.8 & 65.2 & 1.3 & $0.8-2.1$ & 0.264 & 1.5 & $0.9-2.8$ & 0.132 \\
\hline \multicolumn{9}{|c|}{ Intake temperature } \\
\hline $36^{\circ}-37.6^{\circ}$ & 30.8 & 69.2 & & & & & & \\
\hline$<36^{\circ}$ & 46.7 & 53.3 & 1.96 & $1.3-2.9$ & 0.002 & 1.2 & $0.7-2$ & 0.382 \\
\hline $37.7^{\circ}-40^{\circ}$ & 47 & 53 & 1.99 & $1.1-3.5$ & 0.017 & 1.9 & $1-3.5$ & 0.042 \\
\hline \multicolumn{9}{|c|}{ Place of birth } \\
\hline Private structures & 44.6 & 55.4 & & & & & & \\
\hline Hospitals & 30 & 70 & 0.9 & $0.4-1.9$ & 0.817 & 0.8 & $0.5-3$ & 0.543 \\
\hline RHC of Bamako & 40.2 & 59.8 & 0.5 & $0.2-1.2$ & 0.488 & 1.3 & $0.5-3$ & 0.543 \\
\hline $\mathrm{CHC}$ of Bamako & 38.7 & 61.3 & 0.7 & $0.4-1.3$ & 0.350 & 0.8 & $0.3-2.3$ & 0.788 \\
\hline Kati health centers & 33.3 & 66.7 & 0.7 & $0.3-1.7$ & 0.461 & 0.8 & $0.3-2.5$ & 0.811 \\
\hline Other Structures-Mali & 46.8 & 53.2 & 0.6 & $0.3-1.3$ & 0.174 & 1.5 & $0.6-4.1$ & 0.356 \\
\hline \multicolumn{9}{|c|}{ Means of transport } \\
\hline Ambulance & 38.3 & 61.7 & & & & & & \\
\hline Other means & 44.9 & 55.1 & 1.3 & $0.9-1.9$ & 0.194 & 1.7 & $0.6-4.1$ & 0.126 \\
\hline
\end{tabular}


since 2016 until nowadays we see a reversal of the trend with a gradual decrease in references from around $58 \%$ to $53 \%$ (2018) with the increase in reference in born [10] [11] [17]. In our study, we found a frequency of $54.3 \%$ of hospitalizations. This decrease could be explained by the creation of a pediatric unit with the presence of at least two pediatricians in the reference health centers (RHC) of Bamako and the effective presence of the pediatric activity in maternity at the maternity at the Gabriel Toure University Hospital. The same mode of admission to intensive care and neonatal resuscitation services on all continents and especially in Africa as the neonatal referral represents the main mode of admission [9] [18] [19]. In the organization of the health pyramid of Mali is: at the base the first levels of contact of the population with health structures are: the community health center ( $\mathrm{CHC}$ ) and private structures (practices/clinics). The first referral level is the referral health center (RHC). The second referral level is made up of regional hospitals. The third referral level is made up of national hospitals and certain specialized establishments [7] [8]. In relation to the organization and operation of the system; the circuit of the referred patient is organized so that when called by the peripheral structures (CHC and private structures), the ambulance makes the trip to pick up the patient who will be admitted to the RHC. After examination and evaluation of the clinical picture, a diagnosis is made and treatment decided according to the capacities of the RHC. Cases require higher technical table that the level of RHC are evacuated for continuity of care at a university hospital. Thus we found that $19.3 \%$ of references were made directly to the base of the pyramid the Community Health Centers (CHC) and private structures in the neonatal service of the Gabriel Toure University Hospital and 6.7\% (30/450) came from one of the tertiary structures (hospitals). Depending on the level of the system, each health facility should be capable of providing all the packets of minimum activities (PMA) [7] [8]. While the reality is different in our health centers, usually the building is not in the standards, lack of equipment, insufficient staff or otherwise lacks competence to practice birth, emergency neonatal care and continuity of care [20]. We found perinatal anoxia $(15.3 \%)$ as a second reference reason, which shows the benefit of strengthening the skills of staff in neonatal emergency care. This is because childbirth care will have to be reoriented so that the interests of the newborn are duly taken into account [20]. It must start at the first level of the health system, to act on this important factor of neonatal survival which is the place of birth of the newborn [21]. In fact, the transfer of the newborn is indicated if its condition requires care, surveillance or investigations that cannot be carried out in their birth center [3] [6]. The transfer means is chosen according to the severity of the pathology motivating the transfer. The medical ambulance if the newborn is unstable or presents a severe pathology in this context a certain condition must be met (chain of heat, chain of oxygen, chain of sugar, chain of asepsis and chain of information). The non-medical ambulance with a trained nurse and suitable equipment is indicated for the transport of a newborn with mild pathology (no 
mechanical ventilation or non-invasive ventilation in progress) [3] [6] [16] [22]. In our country, the newborn was taken into account in the referral/evacuation system only in 2002 . In 2007 , only $17.4 \%$ of referrals received in the service were made by ambulance [9]. In our series, $71.3 \%$ of references were made by the ambulance and $26.2 \%$ by taxi. And the observation of the high number of transport by taxi made by our peripheral structures, explains the non-respect of the health pyramid by the fact that the ambulance is at the level of the RHC. This increase in the number of ambulance transfers is beneficial but the important thing remains the conditions thereof: the presence on board of a health worker most often not trained in neonatal emergency care and the absence of 'no chains in the ambulances (chains of hot, sugar, oxygen, asepsis and information) [9]. His has been demonstrated in our study that the conveyance was not a determining factor in our context because there was no statistically significant difference between the different means of transport used. Thus, to reduce the morbidity and mortality related to transportation, we must improve the conditions of this [21]. It is therefore urgent in Mali to put in place a means of transport adapted to the condition of the newborn and that our ambulances must be equipped. Neonatal mortality is a heavy burden in developing countries, where newborns continue to die from mostly preventable causes. Reducing neonatal morbidity and mortality requires improving the referral system for newborns in our environment. The four main reasons references found in our study are prematurity (40.2\%), anoxia, or perinatal asphyxia (15.3\%), malformations (15.3\%) and neonatal infections $(9.1 \%)$ represent most of the causes of neonatal deaths found in the world [18] [19] [23] [24] [25].

\subsection{Prognosis of Neonatal References}

On the prognostic level, we found a mortality of $40.2 \%$. This high mortality is found in all sub-Saharan countries [26]. Factors contributing to high mortality of neonatal references observed in our study were preterm, low weight, hypothermia and fever. We found a greater danger of death in newborns who were born more prematurely and or with a very low birth weight. The same observation was found in African studies [26]. The high risk of mortality in this population could be explained by their physical and physiological immaturity [27] [28] [29] [30].

Indeed, the poor transport conditions are very harmful to newborns, and the absence of a normthermal environment, ventilation source or a suitable sugar intake can cause irreversible damage in these infants fragile (premature and/or sick) [26] [27] [28] [29] [30]. In our study, we found that any changes in temperature (hypothermia or hyperthermia) would lead to a significant increase in the risk of death. Hypothermia is a real morbidity factor linked to transport found by Rao SK et al. 2015, Deepak R et al. 2014 and Mathur NB et al. 2007 [29] [30] [31]. There is an urgent need to set up a neonatal referral system that meets all the conditions for secure transfer (the means of transport including all the 
chains, the appropriate equipment and the competent staff). Without respecting these measures, even in ultra-equipped intensive care units, the survival rate will decrease considerably [3] [15] [16] [21] [30].

\section{Limits and Difficulties of the Study}

\subsection{Methodological Approach}

We carried out a cross-sectional study. This type of study makes it possible to take stock of a given question in a given setting, during a given period, taking into account the realities in the field (the hospital). We used data from a survey we carried out in the neonatal ward. The data for this survey were collected retrospectively from a standardized survey form from the medical file and department records.

\subsection{Difficulties Encountered}

During our study, we were faced with problems of completeness some medical records of newborns in the first munites of life such as the Apgar score. Despite these limitations we were able to carry out our work.

\section{Conclusion}

The neonatal referral constitutes the major part of our hospitalizations, i.e. $54.3 \%$ of hospitalizations with still high mortality (40.2\%). The top five reasons for neonatal reference were respectively prematurity, perinatal asphyxia, malformations, respiratory distress and neonatal infections. Thus, reducing this burden requires improving the practice of emergency neonatal care in our health facilities. The establishment of a neonatal reference system meets all the conditions of transfer (the means of transport including all the chains, the appropriate equipment and the competent staff) and is adapted to the clinical condition of the newborn.

\section{Conflicts of Interest}

The authors declare no conflicts of interest regarding the publication of this paper.

\section{References}

[1] Mamelle, N., Maria, B., Rozan, M.A., Claris, O., Crenn, H.C., Pinquier, D., et al. (2003) Take Action to Improve Perinatal Health in the Light of the Results of the AUDIPOG Sentinel Network. Journal of Obstetrics and Reproductive Biology, 32, 617-622.

[2] Miliani, Y., Deruddre, S. and Benhamou, D. (2005) Regionalization of Obstetrics Services and Anesthetic Workload during in Utero Transfers to a Level III Perinatal Center. French Annals of Anesthesia and Resuscitation, 24, 244-248. https://doi.org/10.1016/j.annfar.2004.11.004

[3] Chabernaud, J.L. (2009) Resuscitation of the Newborn in the Delivery Room and Postnatal Transport. EMC; Elsevier Masson SAS, Paris, Pediatrics, 4-002-P-50. 
https://doi.org/10.1016/S1637-5017(09)72440-8

[4] Verónica, R.M., Gallo, L.L., Medina, D.R., De la Torre, M.G., Mancilla, J.-L., Amezcua, M.M., et al. (2011) Safe Neonatal Transport in the State of Jalisco: Impact of the STABLE Program on Morbidity and Mortality. Boletín Médico del Hospital Infantil de México, 68, 31-35.

[5] Ancel, P.Y., du Mazaubrun, C. and Bréart, G. (2001) Multiple Pregnancies, Place of Birth and Mortality of Very Premature Babies: First Results from EPIPAGE Ile de France. Journal de Gynecologie, Obstetrique et Biologie de la Reproduction, 30, 48-50.

[6] Baleine, J.F., Fournier-Favre, P. and Fabre, A. (2016) The Specificity of Neonatal Transport. EMC Pediatricl Child Care, 37, 25-29.

https://doi.org/10.1016/j.spp.2016.07.005

[7] PNS (2015) National Strategic Plan for Essential Care in the Community 2016-2020 Ministry of Health Republic of Mali. National Directorate of Health. Ministry of Health and Public Hygiene, March 2015, 54.

[8] Ministry of Health and Public Hygiene (2018) Newborn Action Plan 2017-2021. MSHP/DNS/DSR, Mali, 119.

[9] Dicko-Traore, F., Sylla, M., Diakite, A.A., et al. (2010) Problem of Neonatal Transfer to the Pediatric Service of the CHU Gabriel Toure in Bamako. Mali Medical, 25, 25-28.

[10] Dicko-Traore, F., et al. (2014) Mali's National Reference Neonatal Unit: State of Play. Public Health, 26, 115-121. https://doi.org/10.3917/spub.137.0115

[11] Mali Ministry of Health and Public Hygiene/Gabriel Toure University Hospital Center (2020) Department of Pediatrics at CHU Gabriel Toure. Annual Activity Report for 2016-2019. Bamako, Mali.

[12] Dicko Traore, F., Diakite, F.L., et al. (2010) P075-Mortality Risk Factors for Premature Newborns at the Gabriel Touré University Hospital in Bamako. Pediatrics Archives, 17, 69. https://doi.org/10.1016/S0929-693X(10)70476-0

[13] Fresson, J., Guillemin, F. andre, M., Abdouch, A., Fontaine, B. and Vert, P. (1997) Influence of the Mode of Transfer on the Short-Term Fate of Children at High Perinatal Risk. Pediatric Archives, 4, 219-226. https://doi.org/10.1016/S0929-693X(97)87234-X

[14] Chabernaud, J.L., Diependaele, J.F. and Menthonnex, E. (2005) Transport of Newborns and Children: History. Emergency Medicine, 27, 343-346.

[15] Chien, L.Y., Whyte, R., Aziz, K., Thiessen, P., Matthew, D., Lee, S.K., et al. (2001) Canadian Neonatal Network. Improved Outcome of Preterm Infants When Delivered in Tertiary Care Centers. Obstetrics \& Gynecology, 98, 247-252. https://doi.org/10.1097/00006250-200108000-00012

[16] Romanzeira, J.C. and Sarinho, S.W. (2015) Quality Assessment of Neonatal Transport Performed by the Mobile Emergency Medical Services (SAMU). The Journal of Pediatrics (Rio J), 91, 380-385. https://doi.org/10.1016/j.jped.2014.10.006

[17] Diakite, M., Diakite, F.L.F., Teyfour Maiga, L., et al. (2019) Pediatrics in the Maternity Unit at the Teaching Hospital Gabriel Toure of Mali: Results of a Year of Activities. Pediatrics \& Neonatal Biology, 4, 1-5.

[18] Desalew, A., Sintayehu, Y. and Teferi, N. (2020) Cause and Predictors of Neonatal Mortality among Neonates Admitted to Neonatal Intensive Care Units of Public Hospitals in Eastern Ethiopia: A Facility-Based Prospective Follow-Up Study. BMC Pediatrics, 20, 160. https://doi.org/10.1186/s12887-020-02051-7 
[19] Verma, J., Anand, S., Kapoor, N., Gedam, S. and Patel, U. (2018) Neonatal Outcome in Newborns Admitted in NICU of Tertiary Care Hospital in Central India: A 5-Year Study. International Journal of Contemporary Pediatrics, 5, 1364-1367. http://www.ijpediatrics.com https://doi.org/10.18203/2349-3291.ijcp20182512

[20] WHO (2005) The World Health Report, Chapter Five: Newborns: We're Finally Interested in Them. WHO, Geneva, 89-112. https://www.who.int/whr/2005/fr

[21] McNamara, P.J., Mak, W. and White, H.E. (2005) Dedicated Neonatal Retrieval Teams Improve Delivery Room Resuscitation of Outborn Premature Infants. Journal of Perinatology, 25, 309-314. https://doi.org/10.1038/sj.jp.7211263

[22] Lavaud, J., Ayachi, A., Chabernaud, J.L. and Lode, N. (2004) Pediatric Resuscitation and Transport. 5th Edition, Elsevier-Masson, Paris.

[23] Antehunegn, G. and Worku, M.G. (2021) Individual- and Community-Level Determinants of Neonatal Mortality in the Emerging Regions of Ethiopia: A Multilevel Mixed-Effect Analysis. Antehunegn and Worku BMC Pregnancy and Childbirth, 21, 12. https://doi.org/10.1186/s12884-020-03506-6

[24] Alebel, A., Wagnew, F. and Petrucka, P. (2020) Neonatal Mortality in the Neonatal Intensive Care Unit of Debre Markos Referral Hospital, Northwest Ethiopia: A Prospective Cohort Study. BMC Pediatrics, 20, 72. https://doi.org/10.1186/s12887-020-1963-Z

[25] Andegiorgish, A.K., et al. (2020) Neonatal Mortality and Associated Factors in the Specialized Neonatal Care Unit Asmara, Eritrea. BMC Public Health, 20, 10. https://doi.org/10.1186/s12889-019-8118-x

[26] Bitew, Z.W., Alemu, A., Ayele, E.G., et al. (2020) Incidence Density Rate of Neonatal Mortality and Predictors in Sub-Saharan Africa: A Systematic Review and Meta-Analysis. International Journal of Pediatrics, 2020, Article ID: 3894026. https://doi.org/10.1155/2020/3894026

[27] Sania, A., Smith, E.R., Manji, K., et al. (2019) Neonatal and Infant Mortality Risk Associated with Preterm and Small for Gestational Age Births in Tanzania: Individual Level Pooled Analysis Using the Intergrowth Standard. The Journal of Pediatrics, 192, 66-72.e4. https://doi.org/10.1016/j.jpeds.2017.09.007

[28] Ray, J.G., Park, A.L. and Fell, D.B. (2017) Mortality in Infants Affected by Preterm Birth and Severe Small-for-Gestational Age Birth Weight. Pediatrics, 6, e20171881. https://doi.org/10.1542/peds.2017-1881

[29] Deepak, R., Adhisivam, B. and Vishnu, B. (2014) Neonatal Transport in Resource Restricted Settings: A Simple Clinical Score at Arrival and Its Role in Predicting Mortality. International Journal of Emergency Medicine, 7, 2. https://doi.org/10.1186/1865-1380-7-S1-P2

[30] Rao, S.K., Bajaj, N. and Rawat, A. (2015) Pre Transport Factors and Transport Quality Affecting the Neonatal Outcome. Journal of Evolution of Medical and Dental Sciences, 12, 1991-1995. https://doi.org/10.14260/jemds/2015/287

[31] Mathur, N.B. and Arora, D. (2007) Role of TOPS (a Simplified Assessment of Neonatal Acute Physiology) in Predicting Mortality in Transported Neonates. Acta Paediatrica, 96, 172-175. https://doi.org/10.1111/j.1651-2227.2007.00006.x 